\title{
Is postural tremor size controlled by interstitial potassium concentration in muscle?
}

\author{
M Lakie, N R Hayes, N Combes, N Langford
}

See end of article for authors' affiliations

....................

Correspondence to: Dr Martin D Lakie, Applied Physiology Research Group, School of Sport and Exercise Sciences, University of Birmingham, Birmingham B15 2T; m.d.lakie@bham.ac.uk

Received 7 July 2003 Revised

28 November 2003

Accepted

29 November 2003
J Neurol Neurosurg Psychiatry 2004;75:1013-1018. doi: 10.1136/jnnp.2003.022749

Objectives: To determine whether factors associated with postural tremor operate by altering muscle interstitial $\mathrm{K}^{+}$.

Methods: An experimental approach was used to investigate the effects of procedures designed to increase or decrease interstitial $\mathrm{K}^{+}$. Postural physiological tremor was measured by conventional means. Brief periods of ischaemic muscle activity were used to increase muscle interstitial $\mathrm{K}^{+}$. Infusion of the $\beta_{2}$ agonist terbutaline was used to decrease plasma (and interstitial) $\mathrm{K}^{+}$. Blood samples were taken for the determination of plasma $\mathrm{K}^{+}$.

Results: Ischaemia rapidly reduced tremor size, but only when the muscle was active. The $\beta_{2}$ agonist produced a slow and progressive rise in tremor size that was almost exactly mirrored by a slow and progressive decrease in plasma $\mathrm{K}^{+}$.

Conclusions: Ischaemic reduction of postural tremor has been attributed to effects on muscle spindles or an unexplained effect on muscle. This study showed that ischaemia did not reduce tremor size unless there was accompanying muscular activity. An accumulation of $\mathrm{K}^{+}$in the interstitium of the ischaemic active muscle may blunt the response of the muscle and reduce its fusion frequency, so that the force output becomes less pulsatile and tremor size decreases. When a $\beta_{2}$ agonist is infused, the rise in tremor mirrors the resultant decrease in plasma $\mathrm{K}^{+}$. Decreased plasma $\mathrm{K}^{+}$reduces interstitial $\mathrm{K}^{+}$concentration and may produce greater muscular force fluctuation (more tremor). Many other factors that affect postural tremor size may exert their effect by altering plasma $\mathrm{K}^{+}$concentration, thereby changing the concentration of $\mathrm{K}^{+}$ in the interstitial fluid.
$\mathrm{H}$ uman physiological tremor has been studied extensively. In this paper we address the question of the factors that determine tremor size. First, we describe some observations on the effect of ischaemia on tremor. We show that ischaemia by itself has minimal effect on tremor size and that a reduction is only produced by a combination of postural muscle activity and ischaemia. We suggest that the reduction of tremor size that occurs with muscular effort in ischaemic muscle may be a reflection of the metabolic accumulation of potassium in the extracellular fluid (ECF) of the muscle, and the effect that this has on muscular contractility. Second, we describe some observations on the increase in tremor size produced by a $\beta_{2}$ agonist, and we suggest that this may be the result of the well established generalised decrease in potassium in the ECF that this drug produces. Finally, we briefly review some well established disparate factors that alter tremor size. We show that these are all compatible with a single mechanism involving alterations in extracellular potassium concentrations in the active muscle which are reflected by alterations in plasma potassium.

Other workers have recently shown that there is a striking inverse relation between tremor size and plasma $\mathrm{K}^{+}$, both in the human ${ }^{1}$ and in animals. ${ }^{2}$ The novel idea that a variety of factors may influence the amplitude of physiological tremor through their effects on extracellular potassium is worth consideration and further study. The simple mechanism that we propose would affect tremor size regardless of how it is generated-it does not matter whether its source is a central oscillator, a reflex mechanism, or neural "noise". In the final analysis, tremor is produced by fluctuating activity of the nervous system. We suggest that interstitial potassium concentration changes the effectiveness with which this is converted into a fluctuating force by the muscles.

\section{Definition of terms}

Postural tremor is a fine shaking of the limbs. It is classically studied by recording the inadvertent motion of a limb (usually the hand) when the subject attempts to hold it in a stationary posture. When hand tremor is recorded by conventional accelerometry it can be seen to possess a more or less rhythmic component, usually with a peak frequency between 7 and $11 \mathrm{~Hz}$. There are several views concerning the reason for this predominant frequency of oscillation, but as far as we know there is only one way of altering the frequency of tremor and that is by changing the mechanical properties of the limb. In this paper we do not concern ourselves with the frequency of the oscillation. However, as will be seen, there are many ways of altering the size of the shake. In this paper we do not address the question of overtly pathological tremors, such as those caused by Parkinsonism or cerebellar disease. Our findings may, however, have implications for one form of essential tremor and its pharmacological treatment.

\section{METHODS \\ Subjects}

We carried out $\beta_{2}$ agonist infusion experiments on 12 subjects (eight male, four female), mean (SD) age 21.4 (1.7) years. Ischaemia experiments were done on six subjects (five male, one female), mean age 37 (9.0) years. Permission was obtained from the local ethics committee, and written informed consent was obtained from the subjects. The experiments conformed with the declaration of Helsinki. All subjects declared themselves to be in good health and none had overt neurological symptoms or were taking $\beta$ agonist or $\beta$ blocker drugs. 


\section{Apparatus}

Hand tremor was recorded using a miniature accelerometer ( 5.0 g; Eurosensor, Towcester, Northants, UK) attached by a tight Velcro ${ }^{\circledR}$ strap above the nail bed of the middle finger of the right hand. Subjects were seated in a comfortable chair which had a shaped polyether foam cradle which supported the right forearm as far as the wrist joint. The unsupported pronated hand was extended and the subject was instructed to maintain it in an approximately horizontal position with the fingers slightly separated. The method and tremor measurements made with it have been described previously. ${ }^{3}$ The acceleration signal was dc amplified so that 1.0 $\mathrm{g}=3.75 \mathrm{~V}$, and an offset was subtracted to null the effects of gravity on the accelerometer. The resulting signal was further amplified with a gain of 2.5 to 25 (to accommodate the subjects' tremor size) and filtered with a passband of 2-40 Hz. The signal was converted by an analogue to digital interface (CED 1401, 12 bit resolution, sampling rate 1000 $\mathrm{Hz}$ ) and stored on a personal computer for subsequent analysis. In these experiments an electromyogram (EMG) was routinely recorded from the active extensor digitorum communis muscle, using surface electrodes with an inbuilt $\times 1000$ gain preamplifier and a passband of $20-350 \mathrm{~Hz}$.

\section{Procedures}

In separate experiments, tremor was recorded after limb ischaemia and following infusion of the $\beta_{2}$ agonist drug terbutaline (Bricanyl sulphate). For the drug trials, cannulae were inserted into the overnight fasted subject, who was allowed to relax for a period of at least 45 minutes, during which three control measurements were made. The drug was infused at a rate of $8 \mu \mathrm{g} \mathrm{kg}^{-1} \mathrm{~h}^{-1}$ through a cannula inserted into the left antecubital vein, over a period of 45 minutes. Venous blood samples were periodically taken from a second cannula implanted in the right antecubital vein. Blood samples were processed and stored at $-80^{\circ} \mathrm{C}$ and were subsequently analysed for plasma $\mathrm{K}^{+}$(indirect ion specific electrode). In these experiments there were infusions of different drugs, dosages, and placebos, with each subject being infused on five occasions. The subject was blind to the agent being infused. We only report here the effects of the terbutaline infusion. In the ischaemia experiments, the recording arrangements were the same. Ischaemia was produced by inflating a cuff placed around the upper right arm to a pressure of $200 \mathrm{~mm} \mathrm{Hg}$. The duration of the ischaemic period was two minutes.

\section{Analysis}

Various procedures can be used to quantify the size of a shake. In these experiments, fast Fourier transform (FFT) analysis was used to calculate the amplitude spectrum of the tremor. The duration of the epoch that was analysed was variable. It was normally $\sim 30$ seconds (ischaemia control measurements) or $\sim 60$ seconds (terbutaline) but was shorter $(\sim 15$ seconds) when tremor size was likely to be changing relatively rapidly (that is, in the ischaemia and muscle activity experiments). The total amplitude in the spectrum between 4 and $14 \mathrm{~Hz}$ was computed and its mean level was calculated and used as an index of tremor size. Most of the power in the tremor acceleration signal lies between $4 \mathrm{~Hz}$ and $14 \mathrm{~Hz}$, and time domain measurements made using root mean square (RMS) values of the waveform, low pass filtered at $40 \mathrm{~Hz}$, revealed a very similar pattern of change. Tremor size commonly reduces in the first few seconds after adopting a posture. To discount this effect we always allowed a period of at least five seconds between adoption of posture and the start of the analysis period. EMG was quantified by determining the area under the spectrum between dc and
$45 \mathrm{~Hz}$. Plasma concentration of $\mathrm{K}^{+}$was expressed as mmol/ litre.

\section{RESULTS}

\section{Ischaemia}

Figure l shows the change in the tremor (raw acceleration signal) in a typical subject. When a posture was maintained continuously during ischaemia, tremor size started to decline progressively after cuff inflation and was strikingly reduced after two minutes. However, when posture was not maintained continuously during ischaemia, there was only a small reduction in tremor size when posture was readopted by the arm after two minutes. When postural activity was restarted after ischaemia under resting conditions, the tremor size again showed a slow progressive decline as the posture was maintained. A substantial reduction in tremor was only apparent when muscular effort was combined with the ischaemia. In contrast to the mechanical record, the visual appearance of the raw EMG signal changed little, suggesting no change in the level of activation.

Figure 2 shows the power spectrum of the tremor signal recorded in the control period compared with the spectrum obtained two minutes after ischaemia, with and without concomitant postural activity. This figure also shows how the size of the tremor signal was quantified for use in the subsequent data analysis. This frequency domain analysis shows that all frequencies of tremor are substantially reduced

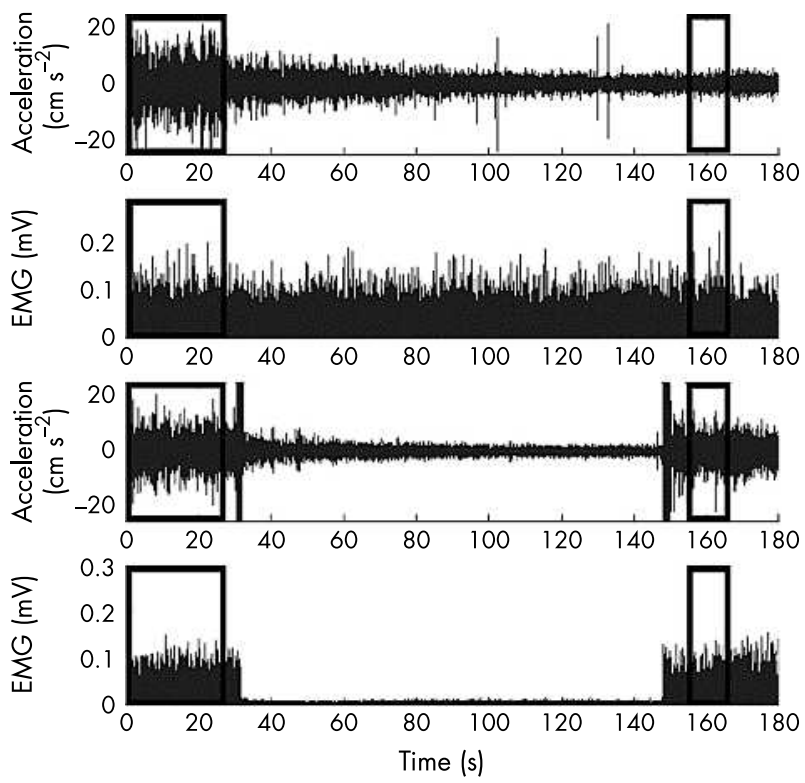

Figure 1 Ischaemia experiment: traces from a typical subject. Tremor is recorded as acceleration of the hand and surface electromyogram (EMG) is recorded from the extensor digitorum communis muscle. The top two traces show the effect of ischaemia plus postural effort. Ischaemia was induced by inflating a cuff round the upper arm as fast as possible starting at 30 seconds. Tremor size declined progressively to about half its initial size after two minutes of ischaemia had elapsed. The EMG trace remained remarkably constant during the complete three minute period. The lower two traces show the changes produced by ischaemia alone. In this case the muscle was relaxed at $\sim 30$ seconds (EMG disappears) and the cuff inflated. When posture was resumed at $\sim 150$ seconds, tremor size was only slightly reduced. The mechanical act of cuff inflation produced some transient vibration of the hand and there was also some passive vibration of the hand in the relaxed condition. A transient increase in tremor size is customarily seen when a posture is first adopted. This can be seen in the lower acceleration trace at $\sim 145$ seconds, when the hand moves into its postural position. It is for this reason that the analysis period which was used for all the records (shown by the heavy rectangular boxes) begins at least five seconds after the adoption of posture. 


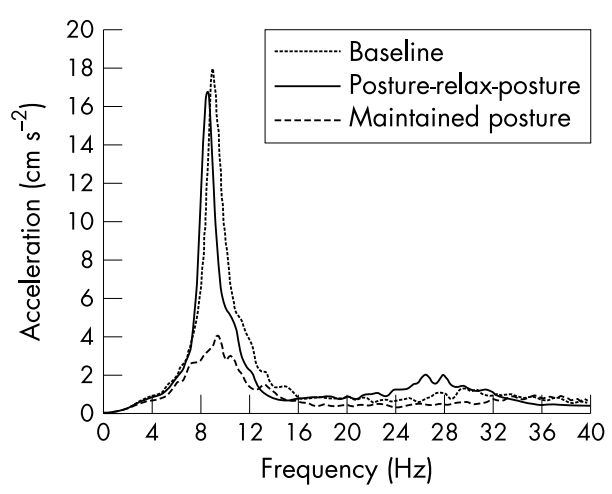

Figure 2 The amplitude spectrum of the tremor acceleration signal for a typical subject. Tremor was quantified by calculating the mean height of the frequency lines between $4 \mathrm{~Hz}$ and $14 \mathrm{~Hz}$. In this example the mean size for the baseline condition was $5.85 \mathrm{~cm} \mathrm{~s}^{-2}$. Maintained posture and ischaemia causes a considerable reduction of the tremor size, whereas ischaemia on its own causes only a small reduction.

by ischaemia, but only when there is accompanying postural activity. Ischaemia on its own only causes a small reduction in tremor size.

Figure 3 shows that for all our subjects the decline in tremor size over a two minute period was related not to ischaemia itself but to ischaemic muscle activity. The overall reduction in tremor size was large, consistent, and rapid when the ischaemic arm is active (mean (SD) reduction, 60 $(10) \%)$ and much smaller and more variable (24 (18)\%) when it was relaxed between measurements. The gross EMG necessary to generate the posture was not significantly different in the two conditions. The envelope of the EMG signal will contain components with similar frequencies to the tremor. The rectified and integrated (leaky integrator $20 \mathrm{~ms}$ time constant) EMG signal was subjected to FFT analysis. The resulting spectrum was divided into three bands, and the power in each was quantified (table 1). There was no significant change in the power in the band associated with tremor frequencies, or in the other two following ischaemia with or without postural effort. Peripheral ischaemia combined with postural effort reduced tremor size without a concomitant change in neural drive.

\section{$\beta_{2}$ Agonist}

Figure 4 shows how tremor size and plasma $\mathrm{K}^{+}$changed in the infusion experiments. Terbutaline infusion began at time zero and lasted for 45 minutes. Tremor size increased steadily and reached a maximum around 60 minutes after the start of infusion (that is, about 15 minutes after the infusion ended). The change in tremor size is mirrored almost exactly by the change in $\mathrm{K}^{+}$, which falls from an initial mean value of 3.75 mmol $\mathrm{l}^{-1}$ to $2.95 \mathrm{mmol} \mathrm{l}^{-1}$ at time 60 minutes. At the end of the experiment ( 30 minutes after the infusion had ended) the tremor size was still increased and the $\mathrm{K}^{+}$was still depressed.

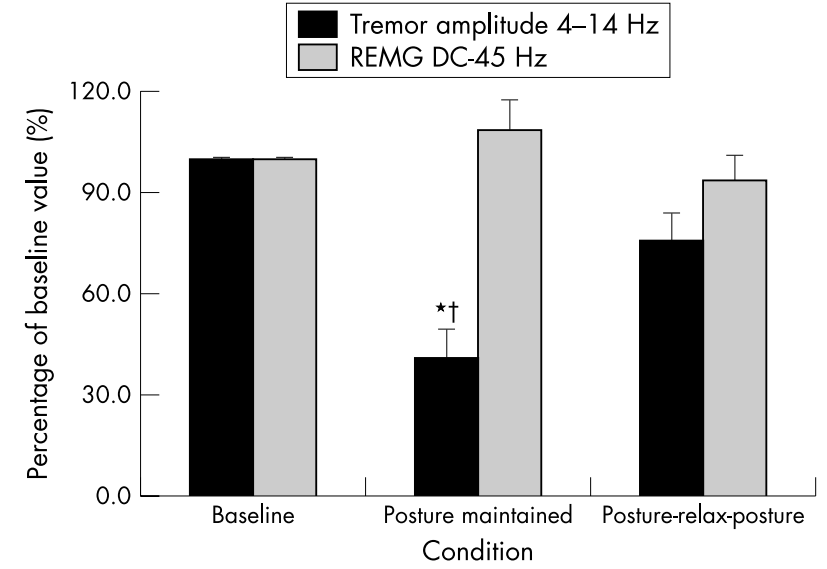

Figure 3 Ischaemia experiments. Tremor and rectified electromyogram (REMG) were measured in the windows shown in fig 1. The size of the tremor and REMG is shown. Ischaemia and a maintained posture produced a large, consistent, and significant reduction (mean (SD), 60 $(10) \%)$ in tremor size $(t=13.43, p<0.05)$. Ischaemia on its own (posture-relax-posture) produced only a much smaller, less consistent, and non-significant reduction (24 (18)\%). The reduction produced by maintained posture was significantly greater than that produced by posture-relax-posture $(t=-4.518, \mathrm{p}<0.05)$. The REMG was not changed by ischaemia and posture or by ischaemia alone. The data were compared by repeated measures $t$ tests (Bonferroni adjusted). Error bars $=$ SEM.

Figure 5 shows the slope of the relation between plasma potassium concentration and tremor size (in absolute units) for individual subjects, based on samples taken at 0, 30, 60, and 90 minutes. A correlation for the data revealed an inverse linear relation between the two variables in 10 of 11 subjects. The coefficient of determinance $\left(r^{2}\right)$ of this relation ranged from $39 \%$ to $99 \%$ and was statistically significant in six subjects $(r>0.878, \mathrm{p}<0.05)$. In the twelfth subject there were inadequate data to plot, and in one subject there was no relation (not shown).

\section{DISCUSSION}

\section{Ischaemia}

Ischaemic reduction of tremor size was originally attributed to changes in muscle spindle sensitivity. ${ }^{4}$ However, the role of muscle spindles in the genesis of this form of physiological tremor is debatable. For example, an artificially produced "tremor" (a small movement of the hand produced by repetitive $\sim 10 \mathrm{~Hz}$ electrical stimulation at low intensity) was also rapidly attenuated by ischaemia. ${ }^{5}$ Thus the effect appeared less likely to be a reflex action and more likely to be a muscular phenomenon, but these investigators were unable to explain its basis, although they suggested it might be a form of "fatigue." Our present observations provide an explanation. The reduction in tremor size is not produced by

Table 1 Electromyographic power spectrum changes

\begin{tabular}{|c|c|c|c|c|}
\hline \multirow[b]{2}{*}{ Band $(\mathrm{Hz})$} & \multicolumn{2}{|c|}{ Maintained posture and ischaemia } & \multicolumn{2}{|c|}{ Posture-relax-posture } \\
\hline & Mean & SD & Mean & SD \\
\hline $\begin{array}{l}4-13.9 \\
14-24.9 \\
25-40\end{array}$ & $\begin{array}{l}102.85 \\
97.05 \\
98.95\end{array}$ & $\begin{array}{l}11.64 \\
13.12 \\
9.82\end{array}$ & $\begin{array}{l}101.50 \\
96.06 \\
102.22\end{array}$ & $\begin{array}{l}11.96 \\
8.08 \\
19.22\end{array}$ \\
\hline
\end{tabular}

The figures are the percentage values where the baseline electromyographic spectrum power has been set to $100 \%$ in each of the three bands. Data from the six subjects were combined. None of the bands is significantly different from the baseline in the maintained posture and ischaemia condition or in the posture-relax-posture condition (paired $t$ tests). 

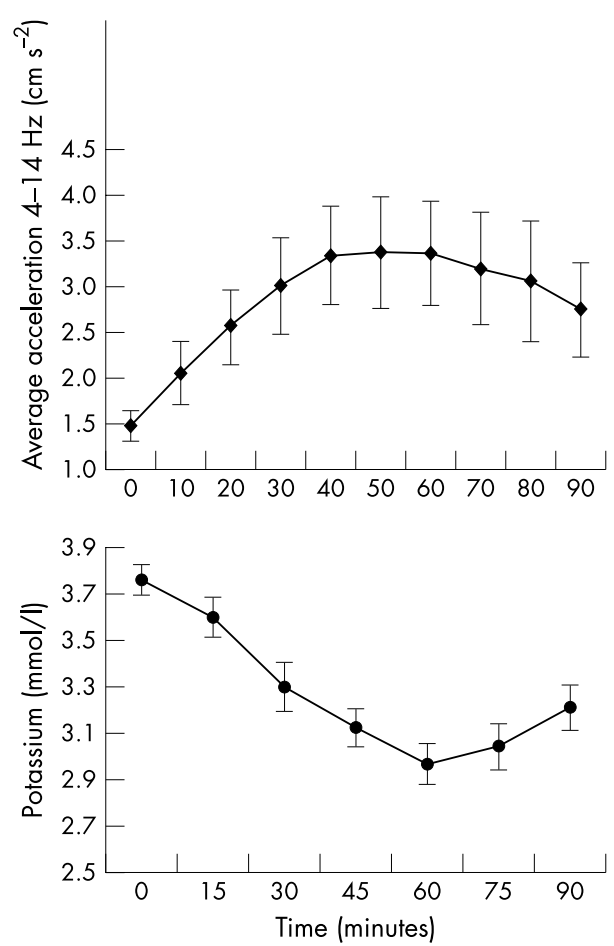

Figure 4 The changes in tremor size (top) and plasma potassium concentration (bottom) produced by the terbutaline infusion in 12 subjects. Values are means, error bars = SEM. It is clear that tremor size almost exactly mirrored the change in plasma potassium concentration. Tremor and potassium were recorded at slightly different intervals. The peak tremor coincided with the lowest $\mathrm{K}^{+}$. The infusion began at time zero and lasted 45 minutes. The changes in tremor and potassium concentration were still continuing 45 minutes after the infusion was ended.

the ischaemia itself but rather by muscular activity in the presence of ischaemia. This has the hallmark of an effect produced by depletion of a substrate or accumulation of a metabolite. We suggest this substance may be $\mathrm{K}^{+}$which accumulates in the ECF of the active muscle. There is no change in the EMG size or frequency spectrum. This further suggests that the reduction mechanism is muscular rather than neural. There was some reduction in tremor in the limb under resting conditions, but in general it was difficult for subjects to maintain the arm in a completely relaxed state.

\section{Infusion of terbutaline}

Terbutaline is a $\beta_{2}$ adrenergic drug and is strongly tremorogenic. The classic experiments by Marsden and coworkers ${ }^{67}$ revealed a considerable increase in postural tremor and a slight decrease in the twitch time of slow muscles when adrenaline was infused. These workers concluded that it was the increase in the fusion frequency of the muscle that led to the great increase in tremor size observed. Thus a frequency of motor unit firing that would normally produce a fused force output would result in an output with much more ripple in the presence of an adrenergic drug. Adrenaline mediated changes in contractile characteristics had earlier been reported in animal studies. ${ }^{8} \beta_{2}$ Agonists are thought to activate membrane located $\beta_{2}$ receptors (first described by Bowman and $\operatorname{Nott}^{9}$ ), altering the twitch properties of muscle as a result of cyclic $3^{\prime}, 5^{\prime}$ AMP released into the muscle cytosol. However, as far as we are aware there is no direct evidence that this pathway is actually involved in the alteration of contractile characteristics. The increase in tremor is uncharacteristically slow. Abila et al commented that "processes

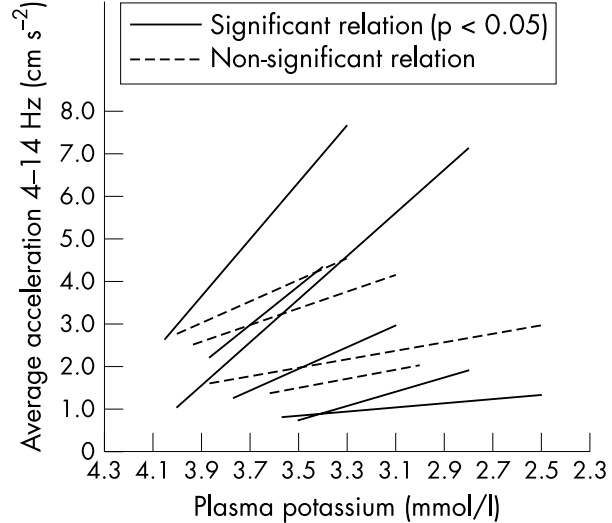

Figure 5 The relation between plasma potassium concentration and tremor size for individual subjects. These are based on samples taken at $0,30,60$, and 90 seconds. There was an inverse linear relation between the two variables in 10 of the 11 subjects for whom there were adequate data (the exception is not shown). The coefficient of determinance $\left(r^{2}\right)$ ranged from $39 \%$ to $99 \%$. The relation was significant in six subjects $(r>0.878, p<0.05)$. The lack of significance for the other four is almost certainly attributable to the very small number of data points for these subjects, which limits significance to those correlations with very high values of $r$. While the overall relation is highly significant (and is evident from fig 4), we thought it was useful to show the relation in our individual subjects.

taking up to one hour to develop would be unusual for mechanisms expected to be mediated via adenyl cyclase ${ }^{\prime \prime}{ }^{10}$ The tremorogenic effect in the present experiments was slow (fig 4). The tremor that can occur when these drugs are used to treat respiratory problems develops some time after the therapeutic effect. The rate constant of the tremorogenic effects of isoprenaline and the tremolytic effects of the selective $\beta_{2}$ blocker propanolol are very much slower than the heart rate responses. ${ }^{10}$

The delayed increase in tremor after a frightening experience which causes an immediate release of adrenaline will be familiar to most people. Also, tremor is the final symptom to appear following the adrenergic response to an insulin induced hypoglycaemic crisis. ${ }^{11}$ We suggest (see below) that the contractile characteristics may be altered not by a specific direct adenyl cyclase mediated action of the drug on muscle $\beta_{2}$ receptors but by the more generalised reduction in $\mathrm{K}^{+}$concentration that it produces by its well established effect on the muscle membrane located $\mathrm{Na}^{+} / \mathrm{K}^{+}$ pump (see for example, Bengtsson ${ }^{12}$ ). Two recent studies ${ }^{12}$ and this one (fig 4) show that tremor size varies reciprocally and simultaneously with plasma $\mathrm{K}^{+}$. This relation might be even clearer were it not for the facts that tremor size is likely to be affected by the rate of change in $\mathrm{K}^{+}$concentration as well as the absolute concentration, and that plasma $\mathrm{K}^{+}$is not a precise indicator of muscle interstitial concentration, although it will reflect it.

\section{The proposed mechanism linking potassium concentration and tremor size}

As excitable cells are relatively permeable to $\mathrm{K}^{+}$ions their membrane potential is close to the equilibrium potential for that ion. Consequently, alterations in extracellular $\mathrm{K}^{+}$will have a profound effect on membrane potential and excitability. As far as the cells of the nervous system are concerned this effect is minimised by the presence of the blood-brain barrier, which is impermeable to $\mathrm{K}^{+}$, and by glial cells which "mop up" $\mathrm{K}^{+}$and distribute it over a larger area ("spatial buffering"). Muscle cells have no such protective mechanism. Muscle fibres represent an enormous reserve of $\mathrm{K}^{+}$which can 
Table 2 Factors associated with alterations in $\mathrm{K}^{+}$and tremor size

\begin{tabular}{|c|c|c|c|c|c|}
\hline Condition & Potassium effect & Tremor effect & $\begin{array}{l}\text { Treatment (if } \\
\text { appropriate) }\end{array}$ & $\begin{array}{l}\text { Explanatory } \\
\text { note }\end{array}$ & References \\
\hline $\begin{array}{l}\text { Adrenaline and other } \beta_{2} \\
\text { agonists }\end{array}$ & $\begin{array}{l}\text { Reduces plasma } \mathrm{K}^{+} \text {by pumping into } \\
\text { muscle }\end{array}$ & Large increase & $\beta_{2}$ Blockers & A & $6,7,8,12,14,15,27$ \\
\hline Hyperthyroidism & Plasma $\mathrm{K}^{+}$is low & Large increase & $\beta_{2}$ Blockers & B & \\
\hline Raised muscle temperature & $\begin{array}{l}\text { Reduced interstitial } \mathrm{K}^{+} \text {because of } \\
\text { increased washout? }\end{array}$ & Large increase & NA & C & 35 \\
\hline Age & Plasma $\mathrm{K}^{+}$generally lower in old age & $\begin{array}{l}\text { Generalised increase in } \\
\text { tremor in old age }\end{array}$ & NA & D & 3,16 \\
\hline $\begin{array}{l}\text { Ethanol withdrawal and } \\
\text { delirium tremens (DT) }\end{array}$ & $\begin{array}{l}\text { Low plasma } \mathrm{K}^{+} \text {only in patients who } \\
\text { develop DT }\end{array}$ & Large increase & $\beta_{2}$ blockers & $\mathrm{E}$ & $17,18,19,20$ \\
\hline Essential tremor & Not known & $\begin{array}{l}\text { Moderate to large } \\
\text { increase }\end{array}$ & $\beta_{2}$ blockers & $\mathrm{F}$ & 21,22 \\
\hline Lithium & Plasma K+ low & Moderate increase & Potassium & G & 23,24 \\
\hline Exercise & Interstitial $\mathrm{K}^{+}$high then low & $\begin{array}{l}\text { Decrease followed by } \\
\text { increase }\end{array}$ & NA & H & $25,26,27$ \\
\hline $\begin{array}{l}\text { Ischaemia and muscle } \\
\text { activity }\end{array}$ & Interstitial $\mathrm{K}^{+}$raised? & Large decrease & NA & I & This paper \\
\hline $\begin{array}{l}\text { Lowered muscle } \\
\text { temperature }\end{array}$ & Interstitial $\mathrm{K}^{+}$raised? & Large decrease & NA & J & 4,35 \\
\hline $\begin{array}{l}\text { Acute ethanol } \\
\text { administration }\end{array}$ & Variable & Large decrease & NA & $\mathrm{K}$ & 29,30 \\
\hline
\end{tabular}

A: The peripheral $\beta_{2}$ receptor associated with tremor is one which controls sodium/potassium exchange (general stimulation of muscle $\mathrm{Na}^{+} / \mathrm{K}^{+}$pumps), rather than one that has a direct effect on the contractile machinery. This hypothesis may explain the delayed tremor response. There are accounts of dramatic tremor and potassium changes with acute clenbuterol poisoning. ${ }^{1 / 15}$

B: Thyrotoxic tremor has been attributed to a synergistic effect of thyroid hormones on adrenaline sensitivity because the tremor is symptomatically "cured" by $\beta$ blockers. Our suggestion is that the tremor is a direct consequence of the low plasma $\mathrm{K}^{+}$caused by the disease. $\beta_{2}$ Blockers ameliorate the tremor by raising extracellular potassium concentration.

C. Small increases in muscle temperature greatly increase tremor size. It may be that the changes are partly consequent on temperature induced changes in blood flow. An increase in muscle blood flow may increase washout of interstitial $\mathrm{K}^{+}$and keep the concentration low, thus enhancing tremor.

D. One study ${ }^{16}$ found "a large prevalence of ... potassium deficiencies in the elderly, an observation we could not attribute to pathology or treatment". The increased tremor of old age ${ }^{3}$ may be related to decreased interstitial $\mathrm{K}^{+}$.

E. The tremor of delirium tremens (DT) is indistinguishable from essential tremor. ${ }^{17}$ Three separate studies have shown that following alcohol withdrawal plasma or total body $\mathrm{K}^{+}$was significantly reduced ${ }^{18-20}$ only in patients who developed DT. Resolution of the tremor was accompanied by return of the plasma $\mathrm{K}^{+}$to normal values.

F. Two studies have reported a weak association between essential tremor size and circulating catecholamines. ${ }^{21}{ }^{22}$ It would be worth investigating whether there is a systematic relation with plasma $\mathrm{K}^{+}$in these patients.

G. Postural tremor is a common problem for patients taking lithium. ${ }^{23}$ Potassium has been employed successfully to treat these side effects. ${ }^{24}$

$\mathrm{H}$. Vigorous exercise results in a subsequent prolonged increase in tremor. ${ }^{25-27}$ This may be attributable to the effects of associated sympathetic release of adrenaline on the $\mathrm{Na}^{+} / \mathrm{K}^{+}$pump, tending to produce a lower interstitial $\mathrm{K}^{+}$concentration, particularly but not exclusively in the muscles which have been active. However, isometric muscle fatigue generally produces a short lasting decrease in tremor size immediately on cessation. ${ }^{28}$ This would be consistent with a period of $\mathrm{K}^{+}$efflux from the muscle and reduced or zero perfusion of the active muscle.

I. Ischaemia only reduces tremor when combined with muscular activity.

J. As in the case of heating (C) this has been attributed to a direct effect on the contractile apparatus. It is possible that a reduction in blood flow and reduced washout of $\mathrm{K}^{+}$may also be a contributory factor.

K. Acute administration of alcohol causes a progressive and profound reduction of both essential tremor ${ }^{29}$ and physiological tremor. ${ }^{30}$ The effect has been generally held to be a central one. However, particularly in the light of the observations on DT above, this could be reinvestigated. If alcohol has a peripheral effect its tremolytic action should be associated with a rise in plasma $\mathrm{K}^{+}$. There is mixed evidence on the effect of acute alcohol intake on plasma $\mathrm{K}^{+}$. Gill et al did report a rise in plasma K+ following alcohol administration, ${ }^{31}$ but Puddey et al reported a decrease ${ }^{32}{ }^{33}$ and Stott et al reported no change. ${ }^{34}$

leak into the interstitium. Although the muscle cell membrane (sarcolemma) is relatively permeable to $\mathrm{K}^{+}$, accumulation in the interstitium does not normally occur at rest because, first, the resting membrane potential is close to the equilibrium potential for potassium; and second, the $\mathrm{Na}^{+} / \mathrm{K}^{+}$ pump (which is active at $\sim 5 \%$ of its maximum level in resting muscle) can prevent accumulation by returning $\mathrm{K}^{+}$ into the cell. In active muscle the situation is very different. There is a considerable efflux of $\mathrm{K}^{+}$from the active muscle, largely as a result of repolarisation by the delayed rectifier $\mathrm{K}^{+}$ channels but also with a contribution from other $\mathrm{K}^{+}$ channels, with the result that $\mathrm{K}^{+}$efflux exceeds $\mathrm{Na}^{+}$influx. The $\mathrm{K}^{+}$in the interstitium is diluted by an increased osmotic interstitial accumulation of water; however, very high local levels of $\mathrm{K}^{+}$have been predicted and observed experimentally. The interstitial concentration of $\mathrm{K}^{+}$is also in equilibrium with capillary blood. As the capillary membrane is permeable to $\mathrm{K}^{+}$there is a flux of $\mathrm{K}^{+}$from interstitium to blood, and the venous effluent from the muscle acts to reduce the local interstitial $\mathrm{K}^{+}$concentration by raising that of the plasma. This equilibrium will be altered if there is any disturbance to muscle blood flow. Although plasma $\mathrm{K}^{+}$will be influenced by the efflux from active muscle this is to a large extent cushioned by the uptake into other inactive muscle. Consequently, although plasma $\mathrm{K}^{+}$does reflect muscular activity it is an imperfect indicator of local interstitial concentration. In severe exercise there is a generalised increase in activity of the $\mathrm{Na}^{+} / \mathrm{K}^{+}$pump which ensures that plasma $\mathrm{K}^{+}$does not usually exceed $5.5 \mathrm{mmol} / \mathrm{l}$ (although extreme values of $8.2 \mathrm{mmol} / \mathrm{l}$ have been recorded). This increased pumping is brought about by $\beta$ adrenergic stimulation of the pump (for a fuller account see Sjogaard and McComas ${ }^{13}$ ).

Whereas increased $\mathrm{Na}^{+} / \mathrm{K}^{+}$pump activity may be able to preserve a near normal transmembrane potential of the muscle cell it is very unlikely that this is the case in the $\mathrm{T}$ tubules. $\mathrm{T}$ tubule permeability to $\mathrm{K}^{+}$is exceptionally high, and the very narrow lumen will restrict diffusion of the ion. $\mathrm{Na}^{+} / \mathrm{K}^{+}$pumps are relatively scarce in the $\mathrm{T}$ tubule. Consequently, inward transmission of the action potential will become increasingly precarious. Also, some delay in activation of the centrally located myofibrils becomes possible. Thus interstitial $\mathrm{K}^{+}$accumulation could cause the characteristic changes toward smaller and slower twitches. Only inward transmission of the impulse into the muscle fibre would be impaired; the EMG recorded from the muscle fibres, which is caused almost entirely by membrane depolarisation/repolarisation, would be little changed. 
We suggest that under postural conditions the local concentration of $\mathrm{K}^{+}$may reach a level where it changes function in that part of the muscle. Postural conditions involve repetitive activation of a small population of small motor units, lack of movement of the muscle, and reduced or absent perfusion. The combination of increased $\mathrm{K}^{+}$efflux and diminished circulatory washout may produce a sufficiently high local interstitial $\mathrm{K}^{+}$to impair the force generation of the muscle fibres that are active. This impairment would act to reduce tremor as a posture is maintained, so in that respect it is not an undesirable feature, but rather an asset. Thus for the small forces associated with tonic postural maintenance the response of the muscle fibres involved will become very much less brisk and the response of the muscles will be blunted.

A depression of plasma $\mathrm{K}^{+}$will be associated with a generally decreased interstitial $\mathrm{K}^{+}$concentration. As a result, muscle function will be less easy to compromise and tremor size will be high. Therefore any factor that reduces plasma $\mathrm{K}^{+}$ should be associated with large tremor size. Conversely, any factor that allows plasma $\mathrm{K}^{+}$to rise should blunt the muscle response and decrease tremor size. A search of published reports shows that many, if not all, conditions associated with changed tremor size have been found to involve altered plasma potassium (table 2). This provides considerable circumstantial evidence in support of our theory.

\section{Conclusions}

Many factors that affect tremor size are also known to affect plasma $\mathrm{K}^{+}$concentration, and by inference, interstitial $\mathrm{K}^{+}$ concentration. This correlation has been reported previously but a cause and effect mechanism has not been proposed. A simple mechanism may link the two factors. By partial blockade of the $\mathrm{T}$ tubule, an increase in interstitial $\mathrm{K}^{+}$can cause muscle function to become changed in such a way that the fusion frequency is reduced. This will produce a much smoother, less pulsatile output of force from the muscle and less tremor in a postural role. This is the mechanism we propose for the reduction in tremor size that is produced by the combination of activity and ischaemia. Conversely, tremorogenic substances and conditions are associated with a reduced plasma and extracellular $\mathrm{K}^{+}$. In these conditions the muscular output will be brisker and force generation will be more pulsatile, predisposing to increased tremor. Our novel suggestion is that, in general, postural tremor size is inversely and causally related to plasma $\mathrm{K}^{+}$concentration.

\section{ACKNOWLEDGEMENTS}

We would like to thank the subjects of these experiments.

\section{Authors' affiliations}

M D Lakie, N R Hayes, Applied Physiology Research Group, School of Sport and Exercise Sciences, University of Birmingham, Birmingham, UK N Combes, Department of Clinical Neurophysiology, New Cross Hospital, Wolverhampton, UK

N Langford, Department of Clinical Pharmacology, Queen Elizabeth Hospital, Birmingham

Competing interests: none declared

\section{REFERENCES}

1 Fowler SJ, Lipworth BJ. Pharmacokinetics and systemic beta(2)adrenoreceptor-mediated responses to inhaled salbutamol. Br J Clin Pharmacol 2001;51:359-62.
2 Tesfamariam B, Wadron T, Seymour AA. Quantification of tremor in response to beta-adrenergic receptor stimulation in primates: relationship with hypokalemia. J Pharmacol Toxicol Methods 1998;40:201-5.

3 Lakie M. Is essential tremor physiological? In: Findley $\sqcup$, Koller WC, eds. Handbook of tremor disorders. New York: Marcel Dekker, 1995:165-83.

4 Lippold OCJ. Oscillation in the stretch reflex arc and the origin of the rhythmical $8-12 \mathrm{c} / \mathrm{s}$ component of physiological tremor. J Physiol (Lond) 1970;206:359-82.

5 Lakie M, Walsh EG, Wright GW. Passive mechanical properties of the wrist and physiological tremor. J Neurol Neurosurg Psychiatry 1986:49:669-76.

6 Marsden CD, Meadows JC. The effect of adrenaline on the contraction of human muscle. J Physiol (Lond) 1970;207:429-48.

7 Marsden CD, Foley TH, Owen DAL, et al. Peripheral $\beta$ adrenoreceptors concerned with tremor. Clin Sci Mol Med 1967;33:53-65.

8 Bowman WC, Zaimis E. The effects of adrenaline, noradrenaline and isoprenaline on skeletal muscle contractions in the cat. J Physiol (Lond) 1958; 144:92-102.

9 Bowman WC, Nott MW. Action of sympathomimetic amines and their antagonists on skeletal muscle. Pharm Rev 1969:21:27-72.

10 Abila B, Wilson JF, Marshall RW, et al. The tremolytic action of $\beta$ adrenoreceptor blockers in essential, physiological and isoprenaline-induced tremor is mediated by $\beta$-receptors located in a deep peripheral compartment. Br J Clin Pharmacol 1985;20:369-76.

11 Arblaster LA. An investigation into some factors which influence human postural tremor. Birmingham: University of Birmingham, 1995. [PhD thesis.]

12 Bengtsson B. Plasma concentration and side effects of terbutaline. Eur J Resp Dis Suppl 1984; 134:231-5.

13 Sjogaard G, McComas AJ. Role of interstitial potassium. In: Gandevia SC, Enoka RM, McComas AJ, et al, eds. Fatigue, neural and muscular mechanisms. New Yotk: Plenum press, 1995

14 Hoffman RJ, Hoffman RS, Freyberg CL, et al. Clenbuterol ingestion causing prolonged tachycardia, hypokalemia and hypophosphatemia with confirmation by quantitative levels. J Toxicol Clin Toxicol 2001;39:339-44.

15 Chodorowski Z, Sein Anand J. Acute poisoning with clenbuterol - a case report. Przegl Lek 1997;54:763-4.

16 Touitou Y, Godard JP, Ferment O, et al. Prevalence of magnesium and potassium deficiencies in the elderly. Clin Chem 1987;33:518-23.

17 Milanov I, Toteva S, Georgiev D. Alcohol withdrawal tremor. Electromyogr Clin Neurophysiol 1996;36:15-20.

18 Watson WS, Lawson PM, Beattie AD. The effect of acute alcohol withdrawal on the serum potassium and total body potassium in heavy drinkers. Scot Med J 1984;29:222-6.

19 Blay SL, Ferraz MP, Calil HM, et al. Plasma electrolyte changes in chronic alcoholic patients with and without delirium tremens. Acta Psiquiatr Psicol Am Lat 1981;27:311-14

20 Wadstein J, Skude G. Does hypokalaemia precede delirium tremens? Lancet 1987;ii:549-50

21 Warren JB, O'Brien M, Dalton N, et al. Sympathetic activity in benign familial tremor. Lancet 1984;i:461-2.

22 Birmingham AT, MacDonald IA. Adrenoreceptors in tremor mechanisms. In: Findley $\amalg$, Koller WC, eds. Handbook of tremor disorders. New York: Marcel Dekker, 1995:119-32.

23 Gelenberg AJ, Jefferson JW. Lithium tremor. J Clin Psychiatry 1995;56:283-7.

24 Cummins MA, Cummins KL, Haviland MG. Use of potassium to treat lithium's side effects. Am J Psychiat 1998;145:895.

25 Gottlieb S, Lippold OCJ. The $4-6 \mathrm{~Hz}$ tremor during sustained contraction in normal human subjects. J Physiol (Lond) 1983;265:821-31.

26 Hagbarth K-E, Young RR. Participation of the stretch reflex in human physiological tremor. Brain 1979;102:509-26.

27 Abila B, Wilson JF, Marshall RW, et al. Exercise induced hand tremor: a possible test for $\beta_{2}$-adrenoreceptor selectivity in man. $\mathrm{Br} J$ Clin Pharmacol 1986;22:104-7.

28 Arblaster LA, Lakie M, Walsh EG. Does brief isometric effort always increase physiological tremor in humans? [Abstract] J Physiol (Lond) 1989:409:5P.

29 Growden JH, Shahani BT, Young RR. The effect of alcohol on essential tremor. Neurology 1975;25:259-62.

30 Lakie M, Frymann K, Villagra F, et al. The effect of alcohol on physiological tremor. Exp Physiol 1994;79:273-6.

31 Gill GV, Bayliss PH, Flear CT, et al. Acute biochemical responses to moderate beer drinking. BMJ 1982;285:1770-3.

32 Puddey IB, Beilin $\sqcup$, Vandongen R. Lack of effect of acute alcohol ingestion on erythrocyte $\mathrm{Na}^{+}, \mathrm{K}^{+}$-ATPase activity or passive sodium uptake in vivo in man J Stud Alcohol 1986;47:489-94

33 Puddey IB, Vandongen R, Beilin $\sqcup$, et al. Alcohol stimulation of rennin release in man: its relation to the hemodynamic, electrolyte, and sympatho-adrenal responses to drinking. J Clin Endocrinol Metab 1985;61:37-42.

34 Stott DJ, Ball SG, Inglis GC, et al. Effects of a single moderate dose of alcohol on blood pressure heart rate and associated metabolic and endocrine changes. Clin Sci (Lond) 1987;73:411-16.

35 Lakie M, Walsh EG, Arblaster LA, et al. Limb temperature and human tremors. J Neurol Neurosurg Psychiatry 1994;57:35-42. 